\title{
FORMULATION AND EVALUATION OF LIQUID ORAL SUSPENSION OF PARACETAMOL USING NEWLY ISOLATED AND CHARACTERIZED HYGROPHILA SPINOSA SEED MUCILAGE AS SUSPENDING AGENT
}

\author{
ANJALI KRISHNA, SHAN MOHANAN* \\ Department of Pharmaceutics, Amrita School of Pharmacy, Amrita Vishwa Vidyapeetham, AIMS - Ponekkara, Kochi, Kerala, India. \\ Email: shanm@aims.amrita.edu
}

Received: 03 August 2018, Revised and Accepted: 26 September 2018

\section{ABSTRACT}

Objective: The objective of this study was to demonstrate and evaluate the suspending property of newly isolated, purified, and characterized Hygrophila spinosa seed mucilage in liquid oral suspensions of paracetamol.

Methods: Isolation of mucilage from $H$. spinosa seeds was done by maceration process, and then it was characterized by phytochemical screening, solubility, $\mathrm{pH}$, swelling index, flow rate, viscosity, loss on drying, and cytotoxicity. The characterized mucilage was then used as a suspending agent for the preparation of suspensions containing paracetamol as a model drug. The prepared formulations were then evaluated for different parameters such as sedimentation volume, redispersibility, flow rate, $\mathrm{pH}$, viscosity, and other physical examination.

Results: The isolated mucilage is a polysaccharide with no impurities and nontoxic in nature. It has got enough swellability and good viscosity. The prepared suspensions were evaluated, and the results such as sedimentation volume, redispersibility, flow rate, pH, viscosity, and other physical examination showed its suspending property.

Conclusion: The study revealed that a lesser amount of $H$. spinosa seed mucilage can produce a good suspension. By this study, it could be find out that a $1 / 5^{\text {th }}$ quantity of mucilage $(0.2 \%)$ is only required to prepare a suspension of paracetamol when compared with suspensions prepared of compound tragacanth (1\%) and sodium carboxymethyl cellulose (1\%) as suspending agents. Thus, by this study, it can be stated that the mucilage from $H$. spinosa possesses all the criteria needed by a standard suspending agent.

Keywords: Hygrophila spinosa, Carboxymethyl cellulose, Suspending agent, Tragacanth, Mucilage, Carboxymethyl cellulose, Sedimentation volume.

(C) 2018 The Authors. Published by Innovare Academic Sciences Pvt Ltd. This is an open access article under the CC BY license (http://creativecommons. org/licenses/by/4. 0/) DOI: http://dx.doi.org/10.22159/ajpcr.2019.v11i11.28856

\section{INTRODUCTION}

India is gifted with a great variety of flora and fauna. The people of the country use it effectively from the past. Due to the several advantages (non-toxic, less expensive, and freely available) of natural materials, nowadays, mankind shows a keen interest in using natural medicines and excipients. Furthermore, they can be modified and made into materials such as pure drugs or components for drug delivery systems [1]. Gums are considered to be pathological products formed by making injury to the plant or due to unfavourable conditions such as drought [2-4]. This would lead to breakdown of cell walls (extracellular gum formation; gummosis). Mucilage is generally normal product of metabolism, formed within the cell (intracellular formation) and or produced without injury to the plant [5-7]. Gums and mucilage have certain similarities - both are plant hydrocolloids. They are also translucent amorphous substances and polymers of a monosaccharide or mixed monosaccharide [8]

A suspension is a pharmaceutical product in which it is a coarse dispersion as insoluble particles $(1 \mu \mathrm{m})$ are dispersed in a liquid aqueous medium. The preparation of suspensions on a small scale, the powdered drug can be mixed with the suspending agent and some of the vehicle. Liquid oral suspension is comparatively quick to prepare and allow in the dosage form. Based on the Noyes-Whitney equation, if the dispersed drug in the suspension has a large surface area, then this will enhance dissolution and increase absorption. The different dosages can be measured from a single strength of preparations. It has been stated that the suspensions were a very useful dosage forms for insoluble or poorly water-soluble drugs for oral administration $[9,10,22]$.
As the use of natural excipients is been profoundly increasing in medicines, in this work, a novel plant mucilage was used for isolating the mucilage. The selected plant was Hygrophila spinosa (Acanthaceae) (Fig. 1), and the seeds were collected for the extraction of mucilage.

\section{MATERIALS AND METHODS}

Materials

Paracetamol was used as the model drug and obtained from Sance pharmaceuticals, Kerala (India). Sodium carboxymethyl cellulose (CMC), compound tragacanth, methylparaben, amaranth, sucrose, acetone, polyethylene glycol, propylene glycol, glycerin, sorbitol, ethyl alcohol, methanol, benzyl alcohol, and isopropyl alcohol other reagents were of the pharmacopeial grade and were obtained from Amrita School of Pharmacy, Kerala (India). H. spinosa seeds were collected from the local market.

Phase 1: Isolation and characterization of $H$. spinosa seed mucilage Isolation of mucilage from $H$. spinosa seeds by maceration process The herbarium of Caesalpinia sappan L. was prepared and authenticated by the botanist, School of Environmental Sciences, Mahatma Gandhi University, India. The seeds (100 g) were boiled with distilled water for $15 \mathrm{~min}$, and the mass was filtered through Buchner funnel without filter paper. The retained residue was boiled with distilled water for $15 \mathrm{~min}$, and the combined liquid was passed through a muslin cloth. The mucilage was precipitated from the filtrate by adding acetone. The precipitated mucilage was dried in an oven at $45^{\circ} \mathrm{C}$ until it was completely dried. The powder then passed through $80^{\#}$ and 


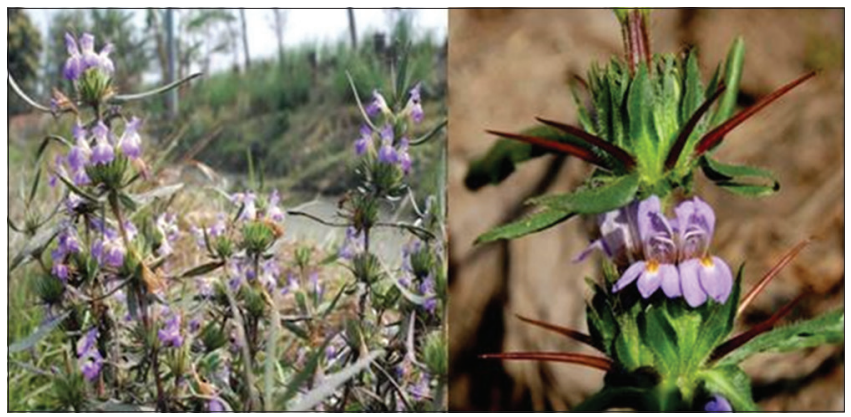

Fig. 1: Hygrophila spinosa in natural habitat showing leaves, flowers, and spines

weighed to calculate the yield, stored in desiccator until for further studies $[7,11,16,17,23]$.

$\mathrm{P}=(\mathrm{Wm} \div \mathrm{Ws}) \times 100$

P: Percentage yield, Wm: Weight of mucilage obtained, Ws: Weight of seeds.

\section{Characterization of $\boldsymbol{H}$. spinosa seed mucilage}

\section{Phytochemical test}

The isolated mucilage was qualitatively analyzed to detect the presence of constituents such as carbohydrates, proteins, flavonoids, tannins, saponins, sterols, alkaloids, and steroids using distinct phytochemical tests [7].

\section{Solubility}

The solubility of isolated mucilage was studied using different types of solvents such as water, acetone, polyethylene glycol, propylene glycol, glycerin, sorbitol, ethyl alcohol, methanol, benzyl alcohol, and isopropyl alcohol [12].

\section{Swelling index}

$1 \mathrm{~g}$ of powdered mucilage was transferred to a $10 \mathrm{~mL}$ graduated cylinder. The initial height of sample was recorded. The sample was added with water and make up the volume to $10 \mathrm{~mL}$, shaken for $5 \mathrm{~min}$, and the powder was allowed to settle [13]. The final swollen height of the sediment was recorded after $24 \mathrm{~h}$, and swelling index was calculated using the formula:

$\mathrm{S}=\{(\mathrm{Hu}-\mathrm{Hi} \div \mathrm{Hi})\} \times 100$

S: Swelling index, Hu: Final height of sediment, Hi: Initial height of suspension.

\section{Loss on drying}

Weighed a glass-stoppered, a shallow weighing bottle that was dried under the same condition to be employed in the determination. $1 \mathrm{~g}$ of sample was transferred to the bottle covered and accurately weighed the bottle and contents. Place the loaded bottle in the oven for $1 \mathrm{~h}$ at $50^{\circ} \mathrm{C}$. After drying, weighs the bottle with content [14].

\section{$\mathrm{L}=(\mathrm{W} 1-\mathrm{W} 2) \div \mathrm{W}$}

L: Loss on drying, W1: Weight of bottle and mucilage before drying

W2: Weight of bottle and mucilage after drying, W: Weight of sample.

$p H$

$\mathrm{pH}$ of the mucilage in water (1\%) was found out using a digital $\mathrm{pH}$ meter.

\section{Viscosity}

The viscosity of the mucilage in water $(0.2 \%)$ was determined at $25^{\circ} \mathrm{C}$ using Ostwald viscometer; all determinations were made in at least triplicate and the results obtained are expressed as the mean values.

\section{Flow rate}

The time required for each sample $(0.2 \%)$ to flow through a $10 \mathrm{~mL}$ pipette was determined, and the apparent viscosity was calculated using the equation

$\mathrm{FR}=\mathrm{V} \div \mathrm{FT}$

FR: Flow rate, V: Volume of pipette (mL), FT: Flow time (s).

Cytotoxicity study: 3-(4, 5-dimethylthialzol-2-yl)-2,5-diphenyl tetrazolium bromide (MTT) assay method

The main reagent, MTT, was prepared in distilled water. Before assay, human hepatocellular liver carcinoma cell lines were subcultured from the stock culture and seeded into multi-well plate. Cells were then incubated at $37^{\circ} \mathrm{C}$ under $5 \% \mathrm{CO}_{2}$ atmosphere. Both positive and negative controls were added along with the samples in duplicate and incubated for $24 \mathrm{~h}$ at $37^{\circ} \mathrm{C}$ in $5 \% \mathrm{CO}_{2}$. After $24 \mathrm{~h}$ of incubation, the samples were taken out added with MTT reagent $(0.2 \mathrm{mg} / \mathrm{mL})$ and kept for incubation for $3 \mathrm{~h}$. Then, after removing the reagent, dimethyl sulfoxide $250 \mu \mathrm{L}$ was added to dissolve the formed MTT formazan crystals. Plates were incubated for $5 \mathrm{~min}$. The absorbance was read out using an automated microplate reader at $620 \mathrm{~nm}[18,19]$.

Phase 2: Formulation and evaluation of liquid oral suspension of paracetamol-containing $\boldsymbol{H}$. spinosa seed mucilage

Formulations of suspension containing paracetamol using optimized seed mucilage, compound tragacanth (1\%), and sodium CMC (1\%)

H. spinosa seed mucilage $(0.2 \%, 0.4 \%, 0.6 \%, 0.8 \%$, and $1 \% \mathrm{w} / \mathrm{v})$ and $1.2 \mathrm{~g}$ of paracetamol were triturated together with $25 \mathrm{~mL}$ of water to form a smooth paste. Then, add $10 \mathrm{~mL}$ of sucrose syrup. The mixture was transferred into a $50 \mathrm{~mL}$ of measuring cylinder made up to volume with distilled water and then shaken vigorously for $2 \mathrm{~min}$ (thus different percentage $\mathrm{w} / \mathrm{v}$ of the mucilage in the preparation). The suspension contains $0.1 \% \mathrm{w} / \mathrm{v}$ methylparaben as a preservative and $0.5 \mathrm{~mL}$ amaranth solution as a coloring agent. The procedure was repeated using $1 \% \mathrm{w} / \mathrm{v}$ of compound tragacanth powder and sodium CMC (1\%) [15].

\section{Optimizing the strength of suspending agent}

The above-prepared suspensions were compared with the standard strengths of tragacanth (1\%) and CMC (1\%). The parameters analyzed were its physical, dispersibility, uniformity, and flow character [16].

Comparative evaluation of these prepared formulations using different methods

Determination of sedimentation volume

Each suspension $(50 \mathrm{~mL})$ was stored in a $50 \mathrm{~mL}$ measuring cylinder for 4 day at $35^{\circ} \mathrm{C}$. Observations were made every $24 \mathrm{~h}$ for 4 day. The sedimentation volume was then calculated using the following equation [17].

$\mathrm{F}=\mathrm{Vu} \div \mathrm{Vo}$

F: Sedimentation volume, Vu: Ultimate sediment volume, Vo: Initial sediment volume.

\section{Redispersibility}

The redispersibility was determined was determined by studying a number of strokes to redisperse the formed sediment at the end of 7 day of storage of the formulations (not $>100$ strokes =redispersibility) [18]. 


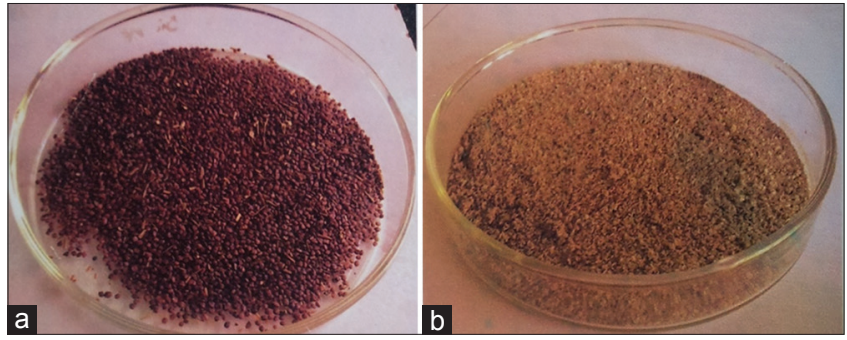

Fig. 2: (a and b) Hygrophila spinosa seeds and mucilage powder

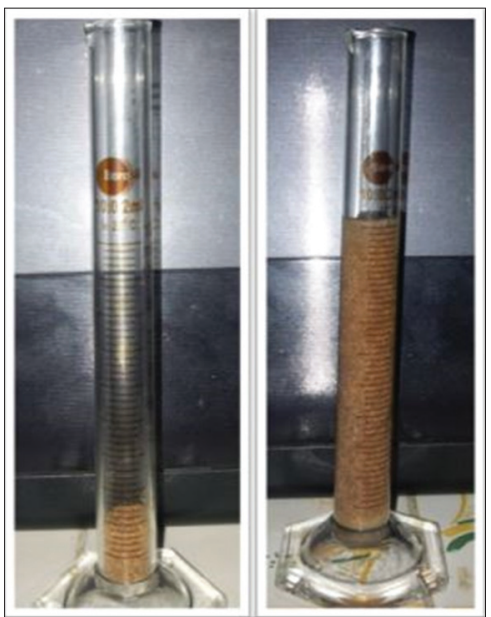

Fig. 3: Swelling of Hygrophila spinosa mucilage before and after addition of water

\section{Determination of flow rate}

The time required for each suspension sample to flow through a $10 \mathrm{~mL}$ pipette was determined, and the apparent viscosity was calculated using the equation.

$\mathrm{FR}=\mathrm{V} \div \mathrm{FT}$

FR: Flow rate, V: Volume of pipette (mL), FT: Flow time (s).

\section{Viscosity}

The viscosity of selected formulations (Compound tragacanth, sodium CMC, and H. spinosa seed mucilage) determined at $25^{\circ} \mathrm{C}$ using Ostwald viscometer. All determinations were made in at least triplicate and the results obtained are expressed as the mean values.

\section{$p H$}

The $\mathrm{pH}$ of selected formulations (compound tragacanth, sodium $\mathrm{CMC}$, and H. spinosa seed mucilage) was determined at $25^{\circ} \mathrm{C}$ using $\mathrm{pH}$ meter [19].

\section{RESULTS AND DISCUSSION}

The mucilage obtained from H. spinosa looks slight brown in color and free-flowing powder. Both the seeds and the purified mucilage powder is shown in Fig. 2.

The percentage obtained was found to be as $35-40 \%$. Percentage yield revealed that $H$. spinosa seeds contain a large amount of mucilage. It is visible when the seeds put in water. It got swelled with a mucilaginous coat over the seed. The phytochemical tests results are shown in Table 1.

The solubility profile shows that the mucilage got dispersed in water then swelled and became highly viscous. In glycerin, the mucilage swelled, but it was not soluble. In other solvents, mucilage is not at all
Table 1: Phytochemical screening of Hygrophila spinosa seed mucilage

\begin{tabular}{lll}
\hline Chemical properties & Test & Results \\
\hline Carbohydrates & Molish test & + \\
Reducing sugars and & Fehling's test and benedicts & + \\
aldehydes & test & \\
Mucilage & Ruthenium red & + \\
Starch & Iodine test & - \\
Alkaloids & Dragendorff's test & - \\
Glycosides & Keller killani test & - \\
Phenols and tannins & Ferric chloride test & - \\
Steroids & Libermann Burchard's test & - \\
Proteins and amino acids & Ninhydrin test & - \\
Flavonoids & Shinoda test & - \\
Terpenoids & Acetic anhydride test & + \\
\hline
\end{tabular}

+: Present, -: Absent

soluble and got sedimented. The swelling index was found to be $90 \%$. The observation showed that as the time increase, swelling index was also increased because weight gain by mucilage was proportional to the rate of hydration (Fig. 3). The direct relationship was observed between the swelling index and mucilage concentration, as mucilage concentration increases swelling index increased. Swelling is one of the parameters which help in suspending the particles in suspension.

The loss on drying was found to be $11.34 \pm 0.23 \%$. The limit is usually $<15 \%$. Hence, this value is found to be within the limit. It indicates the volatile and moisture present in the mucilage. The $\mathrm{pH}$ of mucilage was found to be $5.8 \pm 0.1$. Hence, it can be used in the preparation of suspensions for internal use. The viscosity of $0.2 \%$ aqueous solution of mucilage was found out to be $23.41 \pm 0.56$ poise. The time taken by $1 \%$ aqueous solution of mucilage to flow through pipette was found to be $110 \mathrm{~s}$. The flow rate calculated and the value obtained was $0.0909 \pm 0.01 \mathrm{~mL} / \mathrm{s}$. This indicates a very slow flow nature, and it is mainly due to its high thickening characteristic of mucilage in water, in turn, result in a higher viscosity of the aqueous solution. The viscosity and flow rate study reveal that the suspension which is made out of these mucilage will be with the good suspending property. In the cytotoxic study, the percentage cell viability of the isolated mucilage was found to be $98.51 \%$ (specified limit $>85 \%$ ). Hence, it could be considered a safe excipient. Therefore, it can be used in pharmaceutical and other similar areas as a better substitute for existing suspending agent.

Out of these 7 prepared formulations (Fig. 4), five are made up of different concentrations of mucilage as a suspending agent, one is of compound tragacanth, and the other is with sodium CMC.

The suspension with sodium CMC appeared to be light rose colored, elegant, fairly viscous, and free-flowing. The suspension with compound tragacanth has also with faint rose color, viscous, elegant, and freeflowing. However, in the case of formulations containing mucilage as a suspending agent have different nature. Hence, we analyzed these formulations for a preliminary study to optimize the formulations to make the work easier

\section{Optimizing the strength of suspending agent}

The seven formulations were evaluated. However, the study was begun with a preliminary evaluation of suspensions containing mucilage as a suspending agent. Hence, when these were analyzed, it was found that the formulation containing $0.1 \%$ mucilage was comparatively less viscous but has almost same consistency as that of formulations containing compound tragacanth and sodium CMC as suspending agents. The other formulations with higher percentage of mucilage as suspending agent appeared highly viscous with less flow nature. Hence, these four formulations were omitted from the study. Hence, in the further study, we included only three formulations (Suspensions containing $0.1 \%$ mucilage, $1 \%$ compound tragacanth, and $1 \%$ sodium CMC) 


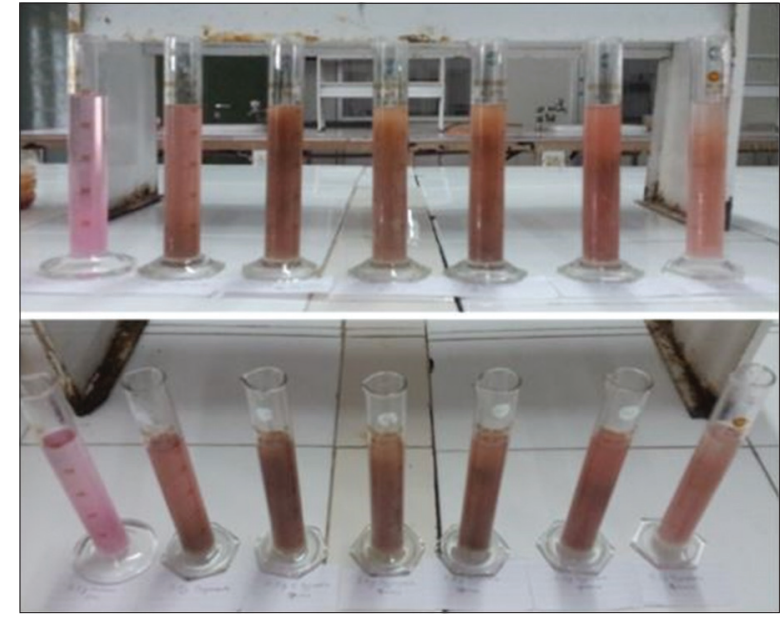

Fig. 4: Suspension containing sodium carboxymethyl cellulose (1\%), compound tragacanth (1\%), and Hygrophila spinosa seed mucilage $(1 \%, 0.8 \%, 0.6 \%, 0.4 \%$, and $0.2 \%)$

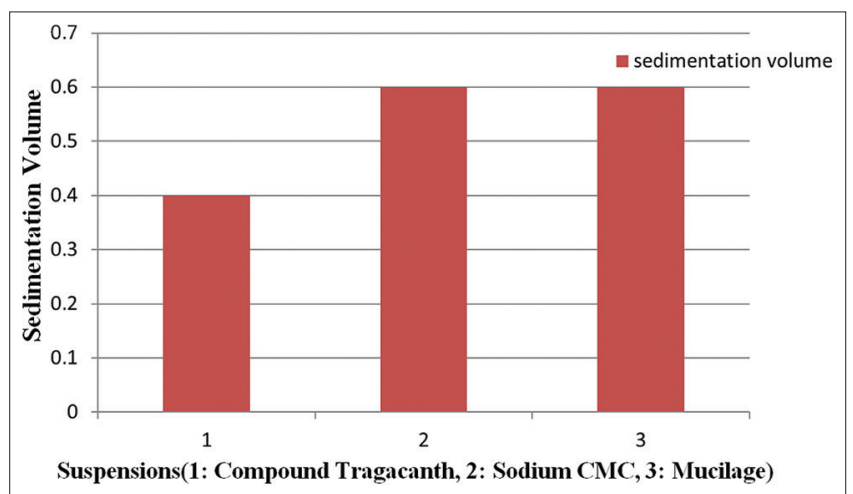

Fig. 5: Sedimentation volumes of formulations

\section{Comparative evaluation of prepared formulations using different} methods

\section{Determination of sedimentation volume}

The result showed that the formulation containing tragacanth has lesser sedimentation volume than the other two formulations (Fig. 5). The formulations with sodium CMC and mucilage are having a value of $0.6 \%$ and were found to be stable.

\section{Redispersibility}

The redispersibility of different suspensions were found out as, compound tragacanth (6 strokes), sodium CMC (5 strokes), and mucilage ( 6 strokes). The data show that the suspensions are easily redispersible and there is no cake formation.

\section{Determination of flow rate}

The flow rate study results were analyzed and the data interpreted as follows. The flow time taken by different suspensions is $0.2 \%$ mucilage $15 \pm 1 \mathrm{~s}, 1 \%$ sodium CMC $13 \pm 1 \mathrm{~s}$, and $1 \%$ compound tragacanth $7 \pm 1 \mathrm{~s}$. Flow rates of suspensions prepared from, compound tragacanth $(1.42 \pm 0.02 \mathrm{~mL} / \mathrm{s})$, sodium CMC $(0.7692 \pm 0.02 \mathrm{~mL} / \mathrm{s})$, and mucilage $(0.6666 \pm 0.01 \mathrm{~mL} / \mathrm{s})$. The flow rate for suspension containing mucilage was found to be less when compared with other formulations. The order of flow rate of suspensions with different suspending agents is as follows:

Compound tragacanth $>$ sodium CMC $>$ H. spinosa seed mucilage

The change in flow rate may be mainly due to the difference in the thickening nature of suspending nature. Here, due to the higher swelling and thickening of mucilage in formulation lead to less flow rate. Hence, the formulation with mucilage as suspending agent experienced difficulty in flow through the pipette and took much time when compared with other two formulations. The viscosity also may be an added factor for the lesser flow rate.

Viscosity

The viscosity obtained as follows, suspension with compound tragacanth (11.326 \pm 0.53 poise), suspension with sodium CMC $(23.613 \pm 1.11$ poise), and suspension with mucilage $(25.674 \pm 0.55$ poise). The viscosities are found to be fairly good and match with that of the limit required by the suspension.

\section{$p H$}

The pHs of formulations were found to be almost equal to that of the marketed formulations. The obtained $\mathrm{pHs}$ are suspension with compound tragacanth $(5.6 \pm 0.1)$, suspension with sodium CMC $(5.2 \pm 0.2)$, and suspension with mucilage $(5.4 \pm 0.1)$. The usual range is 2-6 and is suitable for oral administration. Based on the results of different studies such as sedimentation volume, redispersibility, flow rate, $\mathrm{pH}$, viscosity, and other physical examination it was found that mucilage can be used as a good suspending agent. The suspension with mucilage as the suspending agent has almost all the criteria needed by a suspending agent.

\section{CONCLUSION}

The study revealed that a lesser amount of mucilage can produce a good suspension with all the necessary properties as that of suspensions prepared from compound tragacanth and sodium CMC with a higher amount. By this study, it could be find out that a $1 / 5^{\text {th }}$ quantity of mucilage $(0.2 \%)$ is only required to prepare a suspension of paracetamol when compared with suspensions prepared of compound tragacanth $(1 \%)$ and sodium CMC $(1 \%)$ as a suspending agent. Thus, by this study, it can be stated that the mucilage from $H$. spinosa possesses all the criteria needed by a standard suspending agent.

\section{AUTHOR'S CONTRIBUTIONS}

All the authors have contributed equally.

\section{CONFLICTS OF INTEREST}

Authors have no conflicts of interest.

\section{REFERENCES}

1. Robbins SR. Gum Arabic. In a review of recent trends in selected markets for water-soluble gums. ODNRI Bull 1988;108:18-33.

2. Nakano M, Kouketsu M, Nakamura Y, Juni K. Sustained release of sulfamethizole from agar beads after oral administration to humans. Chem Pharm Bull (Tokyo) 1980;28:2905-8

3. Robert LD. Handbook of Water Soluble Gums and Resins. $2^{\text {nd }}$ ed. New York: McGraw Hill, Kingsport Press; 1980.

4. Bhardwaj TR, Kanwar M, Lal R, Gupta A. Natural gums and modified natural gums as sustained-release carriers. Drug Dev Ind Pharm 2000;26:1025-38.

5. Desai A, Shidhaye S, Malke S, Kadam V. Use of natural release retardant in drug delivery system. Indian Drugs 2005;42:565-75.

6. Qadry JS, Prakashan BS. Shah and Qadry's Pharmacognosy. $12^{\text {th }}$ ed. India, Ahmedabad: Asia Pvt. Ltd.; 2003.

7. Evans WC. Trease and Evans Pharmacognosy. $16^{\text {th }}$ ed. New York: Saunders Ltd.; 2004.

8. Chang RK, Shukla AJ. Handbook of pharmaceutical Excipients. $6^{\text {th }}$ ed. Britain: The Pharmaceutical Press and the American Pharmaceutical Association; 2003.

9. Sripreethi SV. Formulation and evaluation of paracetamol suspension from Trigonella foenumgraecum Mucilage. J Adv Res Edu 2011;1:225-33.

10. Kottke KM. Tablet SR dosage forms. In: Banker GS, Rhodes CT, editors. $3^{\text {rd }}$ ed. Modern Pharmaceutics. New York: Marcel Dekker Incorporated.; 2002. p. 287-333.

11. Aslam VA, Parrott E. Effect of aging on some physical properties of 
hydrochlorthiazide tablets. J Pharm Sci 1971;60:263-6.

12. Chukka S, Puligilla S, Yamsani MR. New formulation and evaluation of domperidone suspension. World J Pharm Pharm Sci 2014;3:1867-84.

13. Ravi K, Swati P, Patil MB, Sachin RP, Mahesh SP. Isolation and evaluation of disintegrant properties of Fenugreek seed mucilage. Int $\mathrm{J}$ Pharm Tech Res 2009;1:982-96.

14. Singh S. Preliminary investigation of Cassia sophera Linn seed mucilage in tablet formulations. Int J Pharm Appl Sci 2010;1:154.

15. Ansari SH. Essential of Pharmacognosy. $5^{\text {th }}$ ed. New Delhi, India: Birla Publications Pvt. Ltd.; 2006.

16. Siddiqui MJ, Ismail Z, Aisha AF, Majid AM. Cytotoxic activity of Catharanthus roseus (Apocynaceae) crude extracts and pure compounds against human colorectal carcinoma cell line. Int J Pharm 2010;6:43-7.

17. Mosmann T. Rapid colorimetric assay for cellular growth and survival: Application to proliferation and cytotoxicity assays. J Iimmunol Methods 1983;65:55-63.

18. Venkata RE. Chemical and biological aspects of selected polysaccharides. Indian J Pharm Sci 1992;54:90-7.

19. Baveja SK, Rao KV, Arora J. Examination of natural gums and mucilages as sustaining materials in tablet dosage forms. Indian $\mathrm{J}$ Pharm Sci 1988;50:89-92.

20. Girish KJ, Dhiren PS, Vipul DP, Vineet CJ. Gums and mucilages: Versatile excipients for pharmaceutical formulations. Asian J Pharm Sci 2009;4:309-23

21. Sheth NS, Shah NV, Shah NC. Extraction of mucilage from Ocimum americanum Linn an its role as disintegrant in tablets formulation. J Glob Pharm Tech 2008;2008:111-68.

22. Michael WK, John AA, David NM, Elikem K. Stability studies on flucloxacillin sodium in reconstituted oral suspensions. Int J Pharm Pharm Sci 2018;10:21-8.

23. Poreddy SR, Penjuri SC, Damineni S, Vuppula S. Formulation and evaluation of colon targeted matrix tablet using natural tree gums. Int $\mathrm{J}$ Pharm Pharm Sci 2018;10:92-7. 